\title{
Arbor
}

\section{La Infantería de Marina, una fuerza para el siglo XXI}

\author{
Francisco González Muñoz
}

Arbor CLXXIII, 682 (Octubre 2002), 301-319 pp.

Nuestra Infantería de Marina es la más antigua del mundo. Sus orígenes se remontan al Tercio de Nápoles de 1537, y desde entonces sus fuerzas han mantenido su tradición naval y expedicionaria con una permanente vinculación a la Armada.

Tras una referencia histórica a las diferentes campañas en que ha participado la Infantería de Marina, el que fue su Comandante General durante los últimos cuatro años nos introduce en las vicisitudes y proceso de evolución de este Cuerpo como componente esencial de la Fuerza Anfibia de la Flota, destacando su versatilidad y capacidad de respuesta a las exigencias de hoy día para actuar como vanguardia de la proyección del poder naval en los nuevos escenarios estratégicos que se nos presentan.

El artículo es una excelente síntesis para quien desee conocer qué.es y cómo opera la Infantería de Marina, cuáles son sus capacidades, medios, organización y estructura, y cómo está adaptándose para afrontar los desafíos del futuro a medio plazo.

\section{La Infantería de Marina española}

Hablar de la historia de la Infantería de Marina es hablar de la historia de España. El origen del Cuerpo se halla en las expediciones marítimas realizadas por los legendarios tercios españoles, que tan brillantemente sirvieron a la Casa de Austria en los siglos XVI y XVII. Desde entonces, y hasta nuestros días, la Infantería de Marina 
ha constituido un cuerpo de tropas permanentemente alistado para desplegar en ultramar en defensa de los intereses nacionales, allá donde se encuentren.

El concepto de Tropas de Marina surge cuando, en 1537, Carlos I vincula en permanencia las Compañías Viejas del Mar de Nápoles a la Escuadra de Galeras del Mediterráneo. En 1566, con ocasión del socorro a Malta frente a la amenaza del sultán otomano Solimán el Magnífico, las citadas Compañías Viejas quedaron refundidas, por orden de la Secretaría de Despacho del rey Felipe II, en una nueva unidad, el Tercio Nuevo de la Mar de Nápoles. Esta unidad, junto con el Tercio de Armada de la Mar Océano, fundado el mismo año, constituirían la primera Fuerza de Desembarco permanente de la historia. La antigüedad de 1537 del Tercio de Nápoles, reiteradamente reconocida por la Corona en diversas disposiciones, confiere a la Infantería de Marina la primacía en antigüedad entre las tropas de marina de todas las naciones.

Los infantes de marina han alcanzando brillantes victorias y demostrado en combate un valor y espíritu de sacrificio insuperables. Sus acciones han acaecido en campos de batalla de las más lejanas partes del mundo y han teñido con su sangre las aguas de todos los mares. Expediciones marítimas, campañas terrestres, guerras civiles y guerras coloniales han puesto a prueba el temple y eficacia de sus unidades, de cuyo brillante historial dan testimonio la Cruz Laureada de San Fernando, la Corbata de Tolosa y las Medallas Militares que orgullosamente ostentan sus banderas.

Desde la creación de la Real Armada en 1717, siempre ha habido un batallón de Infantería de Marina dispuesto a partir en cualquier momento para participar en operaciones por tierra y por mar. Reconocimiento de esta eficaz entrega al servicio son los privilegios militares otorgados a las Tropas de Marina como Cuerpo de Casa Real, distinción alcanzada en 1763, cuando 600 infantes de marina defendieron el castillo del Morro de la Habana frente a los 12000 de la flota británica. Este privilegio, refrendado en 1815 tras la Guerra de la Independencia, se manifiesta en los colores azul y rojo del uniforme y en las sardinetas que luce su bocamanga.

Esta y otras acciones avalan el sobrenombre con que vulgarmente es conocido, El Glorioso (Cuerpo), y refrendan su lema Valientes por tierra y por mar.

Fiel reflejo a su tradición de combate, la Infantería de Marina dispone hoy de una Brigada, BRIMAR, permanentemente alistada para desplegar a través del mar, con el más breve tiempo de alerta, y 
penetrar en fuerza, desde una base a flote, en una costa hostil. Estas posibilidades son inherentes al carácter expedicionario del Cuerpo y a su eminente vocación naval, que le vincula permanentemente a la Flota para constituir un equipo de combate singular, perfectamente preparado para actuar, partiendo de la mar, desde los primeros momentos de la evolución de una crisis.

\section{La Infantería de Marina en el nuevo escenario de la Seguridad Compartida}

Las capacidades de la Fuerza de Infantería de Marina se han revalorizado en el escenario estratégico actual, caracterizado por la necesidad de mantener la paz y la estabilidad internacionales mediante la aplicación, entre otros instrumentos, de fuerzas dotadas de alta movilidad estratégica para operar flexible y oportunamente en zonas alejadas, si es preciso, de sus bases habituales de estacionamiento.

El Nuevo Concepto Estratégico de la OTAN expresa la necesidad de contar con fuerzas de menor entidad que en el pasado, pero dotadas de una serie de capacidades que permitan hacer frente a los nuevos riesgos de carácter multidireccional y multiforme tan difíciles de predecir en cuanto a momento, origen geográfico y forma. Estas fuerzas deben tener un alto grado de alistamiento, ser fácil y rápidamente desplegables, flexibles para adaptarse a las distintas misiones, capaces de mantener presencia avanzada y de operar por largos períodos de tiempo lejos de sus bases. Por otra parte, se enfatiza el contexto multinacional en el que las fuerzas han de empeñarse, símbolo de la cohesión de la Alianza y de su capacidad de disuasión.

En este escenario estratégico, en el que los conflictos armados se desarrollarán en un ámbito regional limitado, el marco habitual de las operaciones de la Armada será el combinado y conjunto. Combinado por las exigencias de la propia Seguridad Compartida, y conjunto porque hoy en día no se conciben las operaciones específicas; sólo lo conjunto permite la maniobra operacional indispensable para actuar en cualquier escenario de crisis. La doctrina de la OTAN amplía su definición de operaciones anfibias para que en ella tengan cabida las nuevas misiones de la Alianza, y así, ya no se habla de una operación lanzada desde la mar contra una costa hostil o potencialmente hostil, sino que, incluso, se recoge la posibilidad de conducir las operaciones anfibias en ambiente permisivo, comprendiendo entre las mismas las operaciones de paz.

Las fuerzas de Infantería de Marina responden de modo sobresaliente a estas exigencias. Desde el primer momento de una crisis, 
pueden desplegar en aguas internacionales y mantenerse por largos períodos en zona, gracias a la capacidad de sostenerlas que poseen los buques de asalto. Operando conjuntamente con fuerzas aerotransportadas se perfilan idóneas como «entry forces», precursoras del despliegue de las fuerzas principales que van a actuar en el teatro. Una vez desplegadas estas fuerzas principales, las de desembarco pueden, posteriormente, ser retenidas a flote como reserva operacional del Comandante de una Combined Joint Task Force $C J T F$ o, en operaciones de alcance limitado, constituir el núcleo del propio componente terrestre.

España, acorde con sus compromisos internacionales y capacidades militares, no sólo tiene la práctica totalidad de sus fuerzas comprometidas para la defensa compartida, sino que ha apostado por la participación activa en las diversas iniciativas multinacionales surgidas tanto en el seno de la OTAN como de la UE. La Armada, en consonancia con esta política y consciente de que el futuro pasa por la pertenencia a estas organizaciones, se ha decidido por la activa participación en todas las iniciativas multinacionales formadas en el marco de la Seguridad Compartida.

No hay que olvidar que las fuerzas multinacionales, desde el punto de vista político, son instrumento de las distintas políticas exteriores, no sólo en el estricto sentido militar, sino en el juego de las relaciones políticas entre las naciones que participan en las mismas, que utilizan estas iniciativas como vías para establecer un determinado "status» nacional y conseguir determinadas influencias dentro de las alianzas. En este sentido, la capacidad de hacer prevalecer los intereses nacionales está en relación directa con las capacidades militares que se aportan. Desde un punto de vista más estrictamente militar, una fuerte aportación permitirá una mayor capacidad de decisión, tanto en el desarrollo de las operaciones como en su planeamiento.

Nuestra Infantería de Marina participa plenamente de las características necesarias para asumir estas misiones. Adiestrada para constituir diversas organizaciones operativas en función de la misión, la BRIMAR es en sí misma una fuerza modular, capaz de proporcionar la entidad y tipo de fuerzas que se precisen en función de las necesidades y tipo de misión. Debe tenerse en cuenta que la BRIMAR tiene sobre sus espaldas décadas de adiestramiento combinado. Mucho antes de que España se integrara en la OTAN, las unidades del Tercio de Armada participaban habitualmente en ejercicios con fuerzas de Estados Unidos y de otras naciones de la Alianza.

Actualmente, la BRIMAR constituye una de las agrupaciones de tropas con mayor capacidad de la Alianza para encuadrar una Brigada 


\section{La Infantería de Marina, una fuerza para el siglo XXI}

Anfibia multinacional. Confirmación de este hecho es la participación de España en todas las fuerzas anfibias de carácter más o menos permanente que se desarrollan en el ámbito aliado y de la Unión Europea (CAFMED, EUROMARFOR, IAE). Muestra del protagonismo que España quiere tener en este ámbito es la creación de la Fuerza Anfibia Hispano-Italiana $S I A F$, que busca complementar las capacidades de las dos naciones para disponer en permanencia de una Brigada combinada, en la que la Infantería de Marina española aporta el grueso de las tropas, la artillería y los principales elementos del Cuartel General.

A partir de 1990 se suceden las operaciones de campo llamadas «Operaciones de Mantenimiento de la Paz» en las que los oficiales de Infantería de Marina toman parte activamente, como muestra del compromiso de España con la paz y con las Organizaciones Internacionales. En 1996, el III Batallón de Infantería de Marina es desplegado en Bosnia-Herzegovina como parte de la Fuerza de Imposición de las Naciones Unidas IFOR. Posteriormente, en 1999, el II Batallón de Infantería de Marina, el llamado Grupo Táctico «Albacete-Fuster», despliega en la misma zona como parte de la Fuerza de Estabilizacion SFOR, siendo relevado ese mismo año por otro que se denomina «Díaz de Herrera».

Desde diciembre de 1999, una unidad de Infantería de Marina viene participando continuamente en las operaciones en $\mathrm{B} \& \mathrm{H}$ como parte de la $S F O R$, realizándose el relevo de la misma cada seis meses.

Hoy, como siempre, la Infantería de Marina está dispuesta para hacer frente a los desafíos del presente y ganar el futuro, firmemente asentada sobre dos pilares: su tradición y su eficacia.

\section{El primer pilar, la tradición naval y expedicionaria}

La tradición naval de la Infantería de Marina parte de su propia fundación en 1537 como Cuerpo de tropas, dos siglos antes de la organización de la propia Institución Naval, con dos características que serán una constante histórica hasta nuestros días: su vinculación permanente a la Armada y su condición de fuerza anfibia, al asumir como misión singular la de realizar desembarcos y golpes de mano utilizando medios y tácticas propios. De esta forma, contemplamos cómo a finales del siglo XVI ya existe una táctica anfibia bien desarrollada que tiene como máximo exponente el desembarco en Azores en 1.583, donde el empleo de embarcaciones especiales, con fondos planos, enviadas a la costa en oleadas sucesivas, y la conquista de "cabezas de playa» como medio para permitir posteriores acciones en tierra, difieren conceptualmente poco de las tácticas modernas. 
En 1.717, con el advenimiento de la Casa de Borbón se produce, bajo el reinado de Felipe $\mathrm{V}$, una reorganización de las instituciones del Estado en las que se ve afectada la Armada y, en consecuencia, las Tropas de Marina. Bajo el eficaz impulso de José Patiño, surge la Real Armada, reorganizándose los regimientos marítimos en el «Cuerpo de Batallones de Marina» que, en 1.766 alcanzaría una fuerza máxima de doce batallones, distribuidos entre las guarniciones de los tres Departamentos de Cádiz, Ferrol y Cartagena. Aunque organizados con vistas a dotar a los buques de guarniciones adiestradas para combatir a flote, los batallones de Marina continuaron teniendo un definido carácter de fuerza expedicionaria, como lo demuestran acciones anfibias de gran envergadura como las de Tolón y Rosas, y en la Guerra contra la Convención Nacional francesa a fines del siglo XVIII.

Tras la Guerra de la Independencia, se suceden las reformas y reorganizaciones derivadas del declinar de una Armada que marcha en paralelo con la atormentada historia nacional. Pero no por eso deja el Cuerpo de escribir páginas gloriosas. Las guerras carlistas y de ultramar decimonónicas reclaman incesantemente Tropas de Marina no sólo para combatir desde la mar, como en las acciones anfibias de Joló y Parang en Filipinas, sino también en las campañas de Santo Domingo, Cochinchina, Méjico e Italia, en las que el Cuerpo da muestras continuas de su capacidad expedicionaria. Esta disponibilidad lleva a los soldados de Marina frecuentemente a campañas terrestres, como las de Cuba, África, cantonales y carlistas, en las que hicieron honor a su lema, valientes por tierra y por mar, pero se alejaron del servicio naval. Con ello, la Infantería de Marina comienza a cuestionarse.

La entrada del siglo XX trajo las pérdidas de las colonias y las derrotas navales de Santiago y Cavite. Tras la repatriación de las tropas de ultramar se producen reformas y recortes financieros, pero en 1911 tropas de Infantería de Marina desembarcan en Larache en una típica intervención desde la mar, para capitalizar la situación favorable que ofrecen los partidarios de España en la zona occidental de Marruecos para la pacificación del Protectorado. La operación alcanza un gran éxito, pero el Regimiento permanece durante años en el Protectorado, dando ocasión en 1914 al Ministerio de Marina para intentar su transferencia al Ejército de Tierra. Si bien no prospera, este episodio no es sino augurio del posterior decreto, firmado por el Gobierno de la Segunda República el 10 de Julio de 1.931, por el que el Cuerpo quedó disuelto.

Tres años más tarde se rectificaba y rellenaba el vacío que en la organización naval había dejado la Infantería de Marina, derogándose 


\section{La Infantería de Marina, una fuerza para el siglo XXI}

su disolución, aunque el Cuerpo quedaba sin misión específica en el seno de la Armada, aparte de la de dotar de guarnición a las Bases Navales. Puede parecer sorprendente que, pese al reciente éxito del desembarco en Alhucemas, la Armada no apostase por una fuerza de desembarco permanente, pero debe tenerse en cuenta que el menos reciente, aunque más resonante, fracaso de la campaña de Gallipolí pesaba aún en la conciencia de la época y que, por otra parte, el Gobierno español a la sazón no era proclive al empleo de la Marina como instrumento de su política exterior, al contrario de lo que era un uso habitual en otras potencias europeas o en Estados Unidos.

Finalmente, la Segunda Guerra Mundial demuestra fehacientemente la practicabilidad e importancia de la capacidad anfibia. En 1953, España comienza a romper el aislamiento internacional que había impedido a las Fuerzas Armadas participar de las enseñanzas de la guerra. La Armada se moderniza y, entre otras dimensiones fundamentales, inicia el desarrollo de una modesta capacidad anfibia moderna. En este clima se gesta, alentada por un grupo de entusiastas oficiales, la regeneración del Cuerpo en la línea de su secular tradición expedicionaria, renovada en la guerra anfibia. Inicialmente, se modernizan sus tropas de Infantería, se las dota de nuevo material, aparecen las primeras unidades de apoyo de combate y de apoyo logístico y se inicia un esfuerzo exhaustivo de formación del personal y de adiestramiento de las fuerzas. Paralelamente, la Armada obtiene buques anfibios cada vez de mayor porte y posibilidades, capaces ya de apoyar el desembarco de un batallón reforzado.

Son años de duro trabajo de organización y preparación, tampoco exentos de actividad operativa. Cuando las circunstancias lo requirieron, la Infantería de Marina volvió a hacerse presente como Fuerza Expedicionaria en las operaciones de Ifni y Sáhara (1957), estableciendo la primera cabeza de playa en la zona de operaciones, mereciendo la distinción del Alto Representante del Gobierno en aquellos territorios.

Una década más tarde, el Decreto 1148/68, de 21 de mayo, corona los esfuerzos de toda una generación de infantes de marina, constituyendo al Tercio de Armada como gran unidad de la Infantería de Marina de la Flota y, sobre todo, atribuyendo a la Infantería de Marina la misión de «llevar a cabo operaciones militares en la costa iniciadas en la mar", es decir, operaciones anfibias. Un largo siglo de crisis orgánicas queda, con ello, superado.

El Tercio de Armada participa también en los últimos hitos del proceso descolonizador. En 1969 fuerzas de Infantería de Marina embarcadas en los buques del «Mando Anfibio» protegen la evacuación 
de súbditos y fuerzas españolas de los antiguos territorios de Guinea Ecuatorial y Sidi Ifni. Pocos años más tarde, durante la crisis del Sáhara Occidental en 1975, el Tercio de Armada constituye y embarca, en tan sólo cuarenta y ocho horas, una fuerza de desembarco de entidad Brigada para apoyar desde la mar al Ejército de Tierra en el Sáhara Occidental. La influencia ejercida por la fuerza de desembarco desde la mar basta para reconducir la situación en el territorio, haciéndose innecesaria la ejecución del desembarco planeado.

Mientras tanto, el Tercio de Armada se pertrecha con material moderno, asimismo de procedencia americana, y recibe equipos de comunicaciones, vehículos con equipos de vadeo, cañones autopropulsados, carros de combate, artillería, camiones anfibios y toda una amplia panoplia de material que le proporciona una potencia de combate muy por encima de la de unidades puramente terrestres de similar entidad. El Cuerpo por fin ha encontrado su misión y se entrega con entusiasmo a ella. La frecuente participación en ejercicios con los americanos le permite no sólo perfeccionar sus tácticas y técnicas sino el adiestramiento con otro tipo de medios de los que aquí se carece, a la vez que va sembrando la semilla de la «multinacionalidad» en la fuerza anfibia.

Decidida a mejorar su capacidad anfibia, la Armada comienza a incorporar buques que aportan nuevas posibilidades operativas. El LSD Galicia y los tres LST,s. Conde del Venadito, Martín Alvarez y Velasco, van a permitir el desembarco de los medios pesados con que cuenta la Infantería de Marina y el lanzamiento de los modernos vehículos anfibios que «revolucionan» el movimiento buque-costa. Aparecen los helicópteros en el panorama anfibio y los COBRAS proporcionan a la fuerza de desembarco el apoyo aéreo cercano de respuesta inmediata.

La fuerza anfibia española se consolida, en ese momento, junto con la británica, como la más importante de Europa. Su capacidad, que le permite desembarcar los escalones de asalto de una fuerza de desembarco de entidad Brigada, es la adecuada para las necesidades derivadas de la estrategia nacional, y lo que es más importante, se ha creado una mentalidad anfibia. El armamento de la fuerza de desembarco incluye artillería de campaña, carros de combate y misiles contracarro, entre otros medios de combate.

Sin embargo, la prioridad que la Armada asume y reconoce sobre el control del Estrecho y sus accesos, dando así preponderancia al escenario Atlántico, hace que en esos momentos primen otros aspectos de la guerra naval. No obstante, la semilla está sembrada, y el Cuerpo inicia un intenso período de actividad intelectual que le lleva al estudio de nuevas fórmulas para la más eficaz explotación de 


\section{La Infantería de Marina, una fuerza para el siglo XXI}

los escasos recursos disponibles, mientras identifica las necesidades que requieren los nuevos conceptos de guerra anfibia que se están desarrollando en los Estados Unidos.

\section{El segundo pilar, la eficacia de la Fuerza de Infantería de Marina para la Flota}

La fuerza anfibia española había comenzado su singladura en el ámbito de una estrategia puramente nacional, en la que prácticamente sólo tenía cabida el asalto anfibio en apoyo de operaciones terrestres de mayor envergadura. Desde su incorporación a la Armada, los primeros buques anfibios procedentes de la «ayuda americana» fueron quedando progresivamente anticuados a lo largo de la década de los setenta. Se trataba de transportes de ataque y buques de desembarco construidos en la Segunda Guerra Mundial, cuyas capacidades operativas sólo permitían la ejecución de un lento asalto frontal por superficie, desde corta distancia de la costa; concepción operativa que, a raíz de la Guerra de Octubre de 1973, empezaba a estar seriamente cuestionada. El papel de las fuerzas anfibias en los flancos de la Alianza Atlántica parecía impracticable, ante la letalidad que cabía esperar en el campo de batalla europeo. Esta visión crítica de la capacidad anfibia daría lugar a una amplia polémica en Estados Unidos sobre la viabilidad de las operaciones anfibias en el futuro.

En 1.982 se produce el ingreso de España en la OTAN, hecho que apenas tiene influencia en el concepto español de las operaciones navales, al compartir nuestra estrategia el mismo adversario que la Alianza. Decididamente, no era precisamente el mejor momento para la regeneración de las fuerzas anfibias españolas. En 1.988 se aprueba el MC-313, que determinaba las directrices para el desarrollo de los Acuerdos de Coordinación de España con la Alianza y, contando con una favorable situación presupuestaria, se promulga el Plan Altamar que establecía el Objetivo de Fuerza de la Armada a medio y largo plazo sobre la base de la estrategia naval vigente, que sólo contemplaba una limitada capacidad de proyección sobre tierra. Pero, un año más tarde, cae el Muro de Berlín y, con él, toda una concepción de la estrategia marítima enfocada primordialmente al control del mar.

Con el final de la Guerra Fría se abre una nueva época, caracterizada por el predominio de la proyección del poder naval sobre tierra. La Armada, ya plenamente en el marco aliado, debe dar respuesta a nuevos desafíos y, con ella, la Infantería de Marina. Ante la configuración del nuevo escenario estratégico, la Marina de los Estados Unidos de- 
sarrolló una nueva estrategia naval, «From The Sea» FTS y «Forward From The Sea» FFTS, basadas en la explotación de las características de fuerza expedicionaria inherentes a la fuerza naval, poniendo el énfasis en la proyección del poder naval, que adquiere importancia capital en la resolución de los nuevos conflictos. Era necesario encontrar una solución para superar la crisis táctica en la que las fuerzas anfibias se hallaban sumidas.

El concepto de Maniobra Operacional desde la Mar OMFTS y el desarrollo de técnicas y tácticas anfibias radicalmente innovadoras serían la respuesta. Ante todo, se conciben los espacios marítimos como un amplio espacio de maniobra para desplegar fuerzas ampliamente dispersas, y concentrarlas rápidamente para golpear los centros de gravedad del adversario partiendo de posiciones a flote a gran distancia de la costa. La aplicación táctica de la OMFTS exigía un asalto anfibio conducido de forma radicalmente distinta al asalto anfibio clásico, desechando los rígidos esquemas del movimiento buque-costa que llevan al asalto frontal de las playas de desembarco, y evitando el alto riesgo que supone la concentración de los buques anfibios fondeados cerca de tierra, procedimientos contrarios a los principios de la guerra de maniobra que inspira el concepto emergente de operaciones desde la mar

Así pues, basándose en los estudios desarrollados durante toda una década por el Marine Corps se formularon los conceptos «Over The Horizon» OTH, «Ship To Shore Maneuver» STSM y «Ship To Objective Maneuver»STOM, con los que se pretende, con ayuda de las nuevas tecnologías, alcanzar en el menor tiempo posible los objetivos en tierra partiendo de los buques de asalto navegando tras la línea del horizonte. Desaparece así la discontinuidad que suponía la línea de costa, y la conquista y ocupación de una cabeza de playa ya no es un requisito esencial en el asalto anfibio. La zona de lanzamiento de los vehículos, helicópteros y embarcaciones se aleja, en la mar, más allá del alcance de los sensores del adversario, disminuyendo la vulnerabilidad de la fuerza, mientras que su capacidad de maniobra permite actuar sobre un amplio sector de la costa actuando en profundidad sobre el despliegue adversario.

Para adaptarse al nuevo escenario estratégico, en 1994 se inició un proceso de renovación de las fuerzas anfibias y de reorganización del Cuerpo. Dos años más tarde vió la luz el «Plan E-01 IM», aprobado por el Almirante Jefe del Estado Mayor de la Armada junto con un programa de renovación de armamento, material y equipo, que deberá estar implantado en su totalidad a finales del 2005. Al mismo tiempo que la Armada se esforzaba por modernizar la fuerza anfibia, el Gobierno 
decidió la total profesionalización de las Fuerzas Armadas, a lo que los planes de la Armada tuvieron que ajustarse. En todo caso, el plan continúa vigente y pretende situar a las fuerzas de IM en el camino para alcanzar, a medio plazo, una capacidad operativa adecuada para capitalizar su empleo en el marco conjunto y combinado como uno de los más versátiles y eficaces instrumentos de la Defensa.

El desembarco $O T H$, en su estricta aplicación, está por ahora fuera de las posibilidades de una mediana potencia naval, pero no por eso la filosofía que sustenta dicho concepto deja de ser imperativa. Aunque nuestras fuerzas anfibias no podrán disponer, al menos en el horizonte previsible, de medios a la altura de la «triada» constituida por el avión de rotor basculante $M V$-22 Osprey, la embarcación de desembarco de colchón de aire $L C A C$ y el Vehículo Avanzado de Asalto Anfibio $A A A V$, el decidido incremento de las capacidades aeromóviles de la fuerza de desembarco, gracias a la potenciación de los helicópteros $A B-212$ y $S H-3 D$ Sea King, la nueva embarcación de desembarco $L C M-1 E$ y los recientemente reconvertidos Vehículos de Asalto Anfibio AAV-7, mejorarán radicalmente las capacidades de las que se disponía diez años atrás y permitirán concebir y ejecutar la maniobra operacional desde la mar.

Estas capacidades se ven apoyadas con la entrada en servicio de los dos LPD,s clase Galicia, que proporcionan las plataformas adecuadas para el lanzamiento a distancia de un número de helicópteros que oscila entre ocho y doce, según los tipos, y de ocho embarcaciones de altas prestaciones $L C M-1 E$ que, en los primeros momentos del asalto, podrán emplearse, incluso, para aproximar a tierra a los vehículos anfibios, junto con otros medios pesados. La filosofía básica que nace de los nuevos conceptos OTH, STOM, STSM, junto con la OMFTS, es por tanto de aplicación para nuestra fuerza anfibia, asumiendo, por supuesto, ciertas limitaciones. No son opciones alternativas al asalto anfibio clásico; estos conceptos marcan el futuro de las operaciones anfibias. Cualquier proyecto o desarrollo tanto en el ámbito del material como en el doctrinal y orgánico deberá ir enfocado a la consecución y mejora de las capacidades $O T H$ de la fuerza anfibia.

El «Plan E-01 IM» pretende adaptar la estructura del Cuerpo, sus unidades y sus medios para hacer frente a los retos del s. XXI. Entre otras decisiones de particular trascendencia, se adopta la de activar la Brigada de Infantería de Marina $B R I M A R$ como una gran unidad elemental de constitución fija (hasta ahora se constituía como una organización operativa con elementos procedentes de diversas unidades orgánicas del Tercio de Armada cuando la ocasión lo requería). Los medios de combate que se integran en la Brigada hacen de ella una 
agrupación de tropas de gran potencia de combate, apta para el asalto anfibio y para la participación en una campaña terrestre cuando sea preciso. Constituye una de las unidades de Infantería de Marina más potentes de nuestro entorno. Su estructura y alistamiento permanente la hacen sumamente flexible y apta para actuar en todo el espectro de actividades militares que el nuevo escenario estratégico pueda presentar.

La BRIMAR dispone de un Cuartel General con capacidad de planeamiento y conducción de operaciones anfibias y terrestres a nivel de Brigada, organizado y equipado para encuadrar unidades de refuerzo y para operar en el ámbito multinacional. La Unidad de Cuartel General encuadra una Compañía de Cuartel General, una Compañía de Comunicaciones y otra de Inteligencia. La primera de ellas engloba al órgano de mando, el Estado Mayor, y a los servicios necesarios para su adecuado funcionamiento. La Compañía de Comunicaciones cuenta con los más modernos medios para garantizar el enlace con las unidades subordinadas y con los buques, lo que incluye el empleo de nuevas tecnologías del campo de la informática y enlace por satélite. Finalmente, la Compañía de Inteligencia agrupa los medios de obtención de información de la BRIMAR (radares, cámaras térmicas y sensores) y el Centro de Interpretación y Difusión de Inteligencia.

La BRIMAR basa su maniobra en tres unidades tácticas fundamentales: dos de Infantería, los Batallones de Desembarco $B D E-I$ y $B D E-I I$ y un tercer Batallón de Desembarco Mecanizado BDMZ-III. Los dos primeros son unidades ligeras, capaces de actuar en cualquier tipo de terreno y bajo cualquier condición meteorológica y de adaptarse con flexibilidad a cualquier tipo de situación en el asalto anfibio. Para ello, pueden ser reforzados con unidades de apoyo para aumentar su movilidad táctica, potencia de fuego y protección. En cuanto al $B D M Z$ III, constituye una fuerza equilibrada de alta potencia de combate, apta para la penetración, la explotación del éxito y, en general, para la maniobra rápida por superficie.

Los $B D E$,s cuentan orgánicamente con tres Compañías de Fusiles, de unos 150 hombres, una Compañía de Armas donde se encuadran las armas de apoyo del Batallón (ametralladoras de $12,7 \mathrm{~mm}$, lanzagranadas automáticos de $40 \mathrm{~mm}$, morteros de $81 \mathrm{~mm}$, misiles contracarro ligeros), y una Compañía de Plana Mayor y Servicios que agrupa diferentes elementos orgánicos, como son el propio Mando y Plana Mayor y la Sección de Reconocimiento, en la que están incluidos los tiradores selectos dotados de fusiles de precisión. 


\section{La Infantería de Marina, una fuerza para el siglo XXI}

Para reforzar a los $B D E$,s, la BRIMAR cuenta con una Compañía de Vehículos Anfibios de Asalto AAV-7 y misiles contracarro pesados TOW, zapadores y otros medios de apoyo de combate. Helicópteros y embarcaciones de todo tipo, desde las más ligeras semirígidas hasta las más pesadas $L C M 1 E$, pueden ser empleados por estas unidades para lanzarse sobre la costa $y$, en su caso, penetrar en el terreno hasta las inmediaciones de sus objetivos en profundidad.

El BDMZ-III dispone de dos Compañías Mecanizadas, que estarán dotadas con vehículos blindados 8x8 Piraña, similares a los que disponen los US Marines y la nueva Brigada Ligera del US Army, y cuya recepción se espera iniciar a finales del 2002. Además, este batallón dispone de una Compañía Acorazada, dotada de carros $M-60$ $A 1$ TTS. EL BDMZ-III, complementa a los BDE,s.

El Grupo de Artillería de Desembarco es el principal elemento de apoyo de fuegos de la BRIMAR. Cuenta con tres baterías de piezas de artillería y una batería de PLM y Servicios. Su composición es heterogénea, por cuanto dos de sus baterías son de $105 \mathrm{~mm}$ remolcadas y la tercera de obuses autopropulsados de $155 \mathrm{~mm} M 109$ A2. Esta composición obedece a la necesidad de proporcionar apoyos de fuego a todos los niveles de la Organización Operativa que pueda constituirse y a las distintas posibilidades de desembarco que se contemplan. Así, las baterías remolcadas pueden desembarcar por medios de superficie o helicópteros, aunque su movilidad en tierra y potencia de fuego sean menores. En cambio, la batería autopropulsada, más ágil y potente en tierra, sólo puede ser desembarcada con embarcaciones $L C M 1 E$.

El Grupo de Armas Especiales agrupa orgánicamente una serie de unidades que proporcionan distintos tipos de apoyo a las unidades de combate. La primera de estas unidades es la Compañía de Misiles Contracarro Pesados $M C C P$,s, dotada con el conocido misil TOW en su versión II, que proporciona fuegos contracarro lejanos a los batallones. La segunda unidad es la Compañía de Vehículos de Asalto Anfibios $A A V-7$, que como hemos dicho proporcionan a los batallones un medio de desembarco, en este caso protegido. Además, esta compañía permite incrementar la movilidad y protección de la mayor parte de un $B D E$. La tercera unidad es la Compañía de Zapadores, que dispone de Secciones de Zapadores y Sección de Maquinaria, y que proporciona el indispensable apoyo en las funciones de movilidad, contramovilidad y protección a la BRIMAR, así como de defensa $N B Q$. La cuarta es la Unidad de Embarcaciones, dotada de balsas semirígidas RHIB, suficientes para poner en tierra hasta una compañía, proporcionando 
un medio de desembarco por superficie veloz y difícil de detectar, muy apto para golpes de mano e incursiones.

El componente aéreo de la BRIMAR descansa en el Grupo Aéreo de Infantería de Marina GRAIM. Esta unidad proporciona defensa antiaérea a baja cota, basándose en su batería de Misiles Antiaéreos Ligeros MAAL Mistral, y proporciona los órganos de control del espacio aéreo que el jefe de la BRIMAR necesita. En el GRAIM se integran, por otra parte, los helicópteros de la FLOAN asignados a la Brigada.

El Grupo de Apoyo de Servicios de Combate GASC cuenta con las unidades necesarias para satisfacer las necesidades de apoyo logístico de la BRIMAR. Para ello agrupa las correspondientes compañías de aprovisionamiento, mantenimiento, transporte y sanidad. Pero, dada la especificidad de la BRIMAR, el GASC cuenta con una unidad singular, la compañía de Organización del Movimiento en Playas $O M P$, que como su propio nombre indica es la encargada de regular el tráfico de unidades, personal y abastecimientos en la playa de desembarco.

Finalmente, dentro de la BRIMAR se encuadra la Unidad de Operaciones Especiales $U O E$, que alcanza un alto nivel como unidad de élite mediante una estricta selección del personal que la compone, procedente de otras unidades del Cuerpo, y que recibe la adecuada cualificación en técnicas de buceo, paracaidismo y navegación, entre otras técnicas especiales. Esta unidad proporciona a la BRIMAR y a la Flota capacidad para desarrollar todo tipo de misiones de operaciones especiales, ya sean de reconocimiento especial, de reconocimiento anfibio o de localización de blancos para los «strikes» aéreos, así como las específicas de acción directa, como destrucciones, rescate de rehenes, y búsqueda y rescate de pilotos. Esta unidad, de unos 140 hombres, cuenta con tres Estoles de Operaciones Especiales, además del correspondiente órgano de mando y Sección de Servicios.

Con estos componentes, se dispone de capacidad para articular diversas Organizaciones Operativas, en función de las características de la misión. Estas agrupaciones pueden ser de muy diferente entidad, desde pequęños destacamentos, como el Equipo Operativo de Operaciones Especiales al que se encomienda una misión concreta, hasta una Brigada Anfibia de Infantería de Marina con la totalidad de la $B R I M A R$ y un importante contingente de helicópteros. Entre estos dos extremos se halla la Agrupación Anfibia de Infantería de Marina AGRAIM -basada en un Batallón Reforzado de Desembarco BRD, una Unidad de Helicópteros y una Unidad de Apoyo Logístico-, capaz de 


\section{La Infantería de Marina, una fuerza para el siglo XXI}

sostener misiones prolongadas de despliegue adelantado a flote en zona de operaciones, de realizar misiones de objetivo limitado y de integrarse en una fuerza multinacional de entidad superior.

\section{La estructura orgánica que sustenta a la Fuerza}

El Cuerpo de Infantería de Marina constituye la estructura orgánica que permite preparar táctica y logísticamente a la Brigada, determinar las necesidades de las fuerzas para dotarlas de los medios de combate necesarios, y facilitar su adecuado empleo, mediante el desarrollo de tácticas y técnicas anfibias y el asesoramiento específico adecuado al Estado Mayor de la Armada. Por otra parte, la Infantería de Marina participa en la estructura de Apoyo a la Fuerza de la Armada para la obtención de recursos y la ejecución de las actividades necesarias para sostener sus unidades.

La Comandancia General, a cuyo frente se encuentra el General de División Comandante General de la Infantería de Marina, se encuadra dentro del Cuartel General de la Armada, e integra a un Estado Mayor como órgano de apoyo al Comandante General en el ejercicio del mando. El Comandante General es responsable ante el Jefe del Estado Mayor de la Armada del adiestramiento y preparación de las fuerzas. Como órgano responsable de la elaboración de doctrina y procedimientos, la Comandancia General dispone, además, de una Junta Táctica JUTIM.

Las fuerzas están constituidas por el Tercio de Armada -que agrupa orgánicamente a las unidades de la Brigada $B R I M A R$ junto con su Unidad de Base- y las Fuerzas de Seguridad. Éstas últimas se organizan en cuatro unidades regimentales, los Tercios Norte, Sur y Levante y la Agrupación de Madrid, que custodian las principales instalaciones en tierra de las Bases Navales y del Cuartel General de la Armada. Asimismo, forman parte de las fuerzas de Infantería de Marina la Compañía Mar Océano de la Guardia Real, las Unidades de Seguridad de las Bases Navales y las guarniciones de buques, representadas únicamente en la actualidad por la del portaaviones Príncipe de Asturias.

En el Apoyo a la Fuerza deben distinguirse dos tipos de elementos. Por un lado están los centros y unidades específicos de Infantería de Marina, que forman parte del Cuerpo aunque dependan orgánicamente de las correspondientes Autoridades de Apoyo a la Fuerza. Por otro, insertos en diversos órganos de la Armada existen unos grupos o secciones de Infantería de Marina que atienden a las necesidades específicas del Cuerpo, desempeñando tareas de asesoramiento o gestión. 
Al primer grupo pertenecen:

La Escuela de Infantería de Marina EIM.

La Escuela de Formación de Tropa de Infantería de Marina ESFORTIM.

El Campo de Adiestramiento Sierra del Retín.

$\mathrm{Al}$ segundo grupo pertenecen:

Los grupos o secciones de Infantería de Marina en la Jefatura de Apoyo Logístico, y en la Jefatura de Personal.

Los grupos de Infantería de Marina de los Arsenales.

La Sección de Infantería de Marina de la Escuela Naval Militar.

\section{Los desafíos del futuro. La Infantería de Marina del 2015}

Aventurarse en el campo de la prospectiva es siempre un ejercicio que exige gran precaución, porque los acontecimientos hoy día se suceden a un ritmo tan dinámico que resulta difícil de predecir su sesgo. La incertidumbre del escenario futuro impide especular, con ciertas expectativas de acierto, acerca de la evolución de la Infantería de Marina más allá del horizonte de los proyectos actualmente en marcha. Ir más lejos constituiría un mero ejercicio imaginativo carente del necesario rigor.

En este contexto, tomando como referencia la situación actual y el objetivo de fuerza establecido en el E01(A)/IM para el año 2.005, parece adecuado establecer como horizonte la fecha del 2.015, en que los proyectos ahora en fase de definición o definitivamente en marcha habrán llegado a su culminación. En cualquier caso, habrá que identificar aspectos aún no contemplados que por constituir carencias esenciales en el futuro, previsiblemente serán abordados o aconsejarán la modificación de proyectos en marcha.

Teniendo en cuenta su evolución en los últimos años, no parece aventurado afirmar que la situación internacional va a mantener la evolución actual, consolidándose un escenario estratégico caracterizado por la ausencia de una amenaza definida contra el territorio de la Alianza y por la aparición de crisis multidireccionales y multiformes de carácter regional que puedan afectar a los intereses nacionales, en un mundo globalizado en el que las amenazas atentan contra la seguridad de todos. La respuesta a estas crisis serán, probablemente, las operaciones de coalición, en las que la medida del protagonismo de la nación en defensa de sus intereses vendrá dado por la importancia de su contribución a la respuesta multinacional.

En este ámbito, las fuerzas anfibias seguirán jugando un importante papel como elementos capaces de proyectar el poder naval sobre tierra, 
lo que acentuará su carácter expedicionario. La profundidad de la «franja litoral» aumentará sustancialmente y, con ella, la necesidad de operar con mucha mayor profundidad en tierra desde la mar, y las fuerzas de Infantería de Marina se aplicarán, con mayor probabilidad, en el ámbito conjunto, especialmente en el marco de las CJTF (Combined Joint Task Forces) cuando sean empleadas como «initial entry forces».

Para operar en estos escenarios será preciso que se hayan adoptado las capacidades y procedimientos de las fuerzas anfibias en el marco de la radical transformación que se está operando en la doctrina aliada.

Por otra parte, en el ámbito nacional, podrían formularse las siguientes hipótesis:

- Se avanzará en la consolidación del marco operativo conjunto.

- El escenario presupuestario no experimentará grandes variaciones y continuará siendo restrictivo.

- Los niveles de incorporación de Marinería y Tropa profesional seguirán siendo bajos e incluso podrían decrecer. Las medidas que se están adoptando para tratar de retener al personal paliarán, en parte, las bajas cotas de captación.

La Infantería de Marina no es más que una parte de la fuerza anfibia, siendo la capacidad operativa de ésta la resultante de la interacción de los elementos de tropas y medios navales que la componen. En el horizonte del 2.015, los LST,s de la clase Hernán Cortés habrán causado baja en el servicio, con lo que se perderá una importante capacidad de transporte. Para paliar esta carencia está en estudio la definición de un nuevo tipo de buque anfibio, que vendría a completar los requerimientos de transporte mínimos para poder desembarcar desde los buques anfibios los escalones de asalto de la Brigada. Aunque el proyecto no está aún definido, puede optarse por un buque de gran porte, con cubierta de vuelo corrida y una capacidad de tropas en torno a los 900 hombres, o dos nuevos buques LPD de características mejoradas a los clase Galicia. Esta capacidad, suficiente para apoyar el Escalón de Asalto de la Brigada, debe completarse, en uno u otro caso, con dos o tres buques auxiliares para el transporte del Escalón Sucesivo de Asalto.

Dicho esto, el futuro presenta a la Infantería de Marina cinco retos fundamentales. El primero es consolidar la Brigada como fuerza de combate plenamente eficaz en operaciones anfibias y expedicionarias. El segundo consiste en mantener un proceso continuo de renovación para adaptarse a las nuevas formas de la guerra anfibia. En tercer lugar, es necesario dotarse de los métodos y medios que le permitan 
hacer frente a los nuevos cometidos emanados del Nuevo Concepto Estratégico. El cuarto es la consolidación de la Infantería de Marina en el marco conjunto y en el combinado. Quinto, y último, es la adaptación del personal a este futuro que se avecina.

Con los proyectos actualmente en marcha, la Infantería de Marina completará la mecanización de su Tercer Batallón, que le conferirá la movilidad táctica, flexibilidad y protección necesarias para actuar en operaciones de combate de mediana intensidad. El reacondicionamiento de los helicópteros $S H-3 D$ para potenciar la capacidad aeromóvil de la fuerza de desembarco, a corto plazo, deberá dar paso a la obtención de nuevas aeronaves, que mejoren sustancialmente las capacidades $O T H$ y de penetración en tierra. La previsible implantación de sistemas de mando y control permitirá, a corto plazo, ejercer eficazmente el mando de una fuerza de desembarco de entidad hasta Brigada, tanto en el ámbito multinacional como en el conjunto. Esta capacidad, convenientemente mantenida y explotada, permitirá a la Infantería de Marina ocupar una posición de liderazgo en el ámbito anfibio tanto de la Alianza como de la UE.

Cara al segundo de los retos, que se dirige a la misión fundamental del Cuerpo, debe afrontarse la necesidad de desarrollar los nuevos métodos de guerra anfibia. La Armada no puede permanecer de espaldas al concepto de Maniobra Operacional desde la Mar y a su correspondiente aplicación táctica. Las unidades operarán necesariamente separadas, posiblemente sin capacidad de apoyo mutuo, por lo que dependerán mucho más de los apoyos procedente de los buques, la aviación o de una artillería de campaña que deberá tener mucho más alcance. Será necesario ocupar, de forma rápida, objetivos tierra adentro, lejos del cordón umbilical de la playa.

Para hacer viables estas formas de guerra anfibia a corto y medio plazo es preciso contar con buques anfibios más flexibles y con mayor capacidad de transporte. Los actuales LST,s son buques de concepción anticuada, con una relación dotación/fuerza embarcada poco rentable y con escasa capacidad de apoyo al desembarco. La entrada en servicio de, al menos, un nuevo LPD es una medida que debe considerarse urgente para conservar las posibilidades hoy existentes.

En cuanto a helicópteros, la transformación de los $S H-3 D$ supondrá un gran impulso para la fuerza de desembarco, pero será preciso acompañar esta medida, en el mismo sentido, con la modernización de la $3^{\text {a }}$ Escuadrilla y el desarrollo del adecuado sistema de control del espacio aéreo, así como la activación de una Unidad de Apoyo al Despliegue para apoyar a las aeronaves en tierra. Estas medidas serán esenciales 


\section{La Infantería de Marina, una fuerza para el siglo XXI}

para conseguir la más flexible y plena integración de las aeronaves y sus medios de apoyo en un solo componente de la fuerza de desembarco, si se desea obtener de ellas el mayor rendimiento operando en profundidad en tierra.

El tercero de los retos supone asumir misiones hasta ahora no contempladas. El refuerzo a la actuación de la autoridad civil contra la acción del crimen organizado y todo el espectro de misiones de paz o de ayuda humanitaria, son ejemplos de estas misiones. Para ello, será necesario dotarse de armamento no letal, de equipos de protección adecuados para actuar en zonas urbanas y desarrollar una capacidad específica para participar en Operaciones de Interdicción Marítima. Por su parte, la mecanización del BDMZ-III proporcionará una unidad muy apta, dada su protección basada en vehículos de rueda, para participar en operaciones de interposición.

El empleo de la fuerza debería evolucionar para alcanzar la capacidad de mantener desplegada una Agrupación Anfibia de Infantería de Marina AGRAIM que responda al concepto SOC (Special Operations Capability) de los MEU (Marines Expeditionary Unit) del US Marine Corps. Será preciso dotar a la $U O E$ de más y mejores equipos a la altura de las mayores exigencias operativas que esta unidad tendrá que afrontar y modificar el adiestramiento de las unidades de Infantería para hacerlas aptas para realizar misiones tipo comando.

Respecto al cuarto reto, la Infantería de Marina debe incrementar la actual cobertura de plantillas para estar en disposición de aportar entidades de fuerza que garanticen su situación a la cabeza de las naciones europeas. El contar con un sistema de mando y control fiable y capaz de asumir los refuerzos tiene que ser un objetivo prioritario. El SIMACET, compartido con el Ejército de Tierra y totalmente compatible con el sistema ACCIS aliado, dará pronta solución a este problema. Finalmente, hay que impulsar el desarrollo de los procedimientos comunes que garanticen el correcto funcionamiento de las fuerzas.

Pero el principal reto que tiene la Infantería de Marina para afrontar el futuro de protagonismo que le aguarda, está en la obtención, formación y motivación de su personal, adecuado en cantidad y calidad a la gran variedad de funciones y equipos que integran sus sistemas y medios de combate. Y sobre todo, sus hombres deben ser combatientes de élite, física y moralmente preparados para ser dignos, en el servicio de las armas, del lema escrito en la historia por los Infantes de Marina que les han precedido: VALIENTES POR TIERRA Y POR MAR. 